\title{
A Proposed Approach to Chronic Airway Disease (CAD) Using Therapeutic Goals and Treatable Traits: A Look to the Future
}

This article was published in the following Dove Press journal: International Journal of Chronic Obstructive Pulmonary Disease

Luis Pérez de Llano, (ID' Marc Miravitlles, (D) ${ }^{2}$ Rafael Golpe,' Francisco Javier Alvarez-Gutiérrez, (iD) ${ }^{3}$ Carolina Cisneros, ${ }^{4}$ Carlos Almonacid, (iD) ${ }^{5}$ Eva Martinez-Moragon, ${ }^{6}$ Francisco-javier Gonzalez-Barcala, (iD) ${ }^{7}$ David RamosBarbón, (iD) ${ }^{8}$ Vicente Plaza, (iD ${ }^{8}$ Jose Luis Lopez-Campos, (iD) ${ }^{3}$ Juan Pablo de-Torres, ${ }^{9}$ Ciro Casanova, ${ }^{10}$ Juan Luis Garcia Rivero," Juan Rodriguez Hermosa, (iD) ${ }^{12}$ Myriam Calle Rubio, (iD) ${ }^{12}$ Juan Jose Soler-Cataluña, ${ }^{13}$ Borja G Cosio (iD ${ }^{14}$

'Pneumology Service, University Hospital Lucus Augusti, Lugo, EOXI Cervo, Lugo, Monforte, Spain

${ }^{2}$ Pneumology Service, Hospital Universitari Vall d'Hebron, Vall d'Hebron Institut de Recerca

(VHIR), Vall d'Hebron Barcelona Hospital Campus, CIBERES, Barcelona, Spain; ${ }^{3}$ Pneumology Service, Hospital Universitario Virgen del Rocio, Seville, Spain; ${ }^{4}$ Pneumology Service, La Princesa University Hospital, Madrid, Research Institute La Princesa IIP, Madrid, Spain; ${ }^{5}$ Pneumology Service, Ramón y Cajal Hospital (Ramon y Cajal Health Research Institute, IRYCIS), Madrid, Spain; ' ${ }^{6}$ Pneumology Service, Hospital Universitario Dr Peset, Valencia, Spain; ${ }^{7}$ Faculty of Medicine at the University of Santiago de Compostela, Pneumology Service of the University Clinical Hospital of Santiago de Compostela, CIBERES, Santiago de Compostela, Spain; ${ }^{8}$ Pneumology Service, Hospital de la Santa Creu i Sant Pau, Barcelona, Spain; 'Division of Respirology and Sleep Medicine, Queen's University, Canada, ON, Canada; ${ }^{10}$ Pneumology Service, Hospital Universitario Nuestra Señora de Candelaria, Santa Cruz De Tenerife, Spain;

"Pneumology Service, Hospital de Laredo, Laredo, Spain; ${ }^{12}$ Pneumology Service and Faculty of Medicine, Hospital Clínico San Carlos,

Complutense University of Madrid, Madrid, Spain:

${ }^{13}$ Pneumology Service, Hospital Arnau de Vilanova, Valencia, Spain; ${ }^{14}$ Pneumology Service, Son Espases University Hospital, IdISBa, CIBERES, Clínica

Quirón-Rotger, Palma, Spain

Correspondence: Borja G Cosio

Pneumology Service, Hospital Universitario Son Espases, IdISBa, CIBERES, Clínica Quirón-Rotger, Ctra. de Valldemossa 79, Palma de Mallorca 070I0, Spain

Tel +34871 206714 Ext 76714

$\mathrm{Fax}+34871909724$

Email borja.cosio@ssib.es
Abstract: Chronic airflow obstruction affects a wide range of airway diseases, the most frequent of which are asthma, COPD, and bronchiectasis; they are clearly identifiable in their extremes, but quite frequently overlap in some of their pathophysiological and clinical characteristics. This has generated the description of new mixed or overlapping disease phenotypes with no clear biological grounds. In this special article, a group of experts provides their perspective and proposes approaching the treatment of chronic airway disease (CAD) through the identification of a series of therapeutic goals (TG) linked to treatable traits (TT) - understood as clinical, physiological, or biological characteristics that are quantifiable using biomarkers. This therapeutic approach needs validating in a clinical trial with the strategy of identification of TG and treatment according to TT for each patient independently of their prior diagnosis.

Keywords: airflow obstruction, biomarker, personalised medicine, COPD asthma overlap

\section{Introduction}

Current definitions identify the classical patterns (clinical and biological) of asthma and COPD unequivocally. However, the heterogeneous nature of both processes and their overlap in some cases has given rise to intense research in order to define more homogeneous groups of patients on the basis of phenotypes or endotypes. This problem is not new and was pointed out as far back as 1987 by Burrows et al, who described a group of patients (with what they called "asthmatiform bronchitis") who had a clinical evolution and prognosis that lay between asthma and $\mathrm{COPD}^{1}$ supporting the view of a common origin of asthma and COPD, the socalled Dutch hypothesis. ${ }^{2}$ Recent studies of lung function trajectories in COPD also support the influence of early childhood asthma in early lung development. ${ }^{3}$ This is now known as asthma-COPD overlap (ACO). ${ }^{4}$ ACO is a theoretical construct with no clear biological grounds and with an imprecise definition that encompasses both long-standing asthmatics who smoke and develop chronic airflow obstruction, and patients with COPD who have blood eosinophilia or greater reversibility after a bronchodilator test, ${ }^{5}$ even though they have been shown to be very different from each other. ${ }^{6}$

Some authors have already proposed leaving behind the approach based on phenotypes or endotypes in order to adopt a pragmatic view through the identification of "treatable traits" (TT) for each particular patient. ${ }^{7,8}$ However, this novel 
approach contains a few inaccuracies as there is some confusion as to what TT really are, and which ones should be taken into account. The article published by McDonald et $\mathrm{al}^{9}$ defines them as "therapeutic targets identified by the phenotype or endotype through validated biomarkers". This publication puts forwards lists with different TT that leave out cardinal symptoms such as dyspnoea while including others such as "smooth muscle contraction" or "oedema of the bronchial mucosa", which are of doubtful clinical significance. What is more, contradictorily, blood or sputum eosinophilia is considered a TT, whereas at the same time it is claimed not to be a TT, but rather a "TT biomarker".

With the present document, a group of authors in the areas of asthma and COPD from the Spanish Society of Pneumology and Thoracic Surgery (SEPAR) aims to provide their insight with regard to the therapeutic approach based on TT, by overcoming some inaccuracies so that this may be applicable in clinical practice, and be able to serve as a basis for a clinical trial in order to prove its effectiveness. Further, we argue that the therapeutic goals (TG) set for each patient must be considered separately from the TT upon which action can be taken in order to achieve them.

\section{Operational Definition of Chronic Airway Disease (CAD)}

The proposal is to group patients who have Chronic Airflow Obstruction under the common denomination of Chronic Airway Disease (CAD) - defined as an obstructive spirometry pattern with post-bronchodilator $\mathrm{FEV}_{1}$ /FVC below 0.70 - independently of the underlying etiopathogenic mechanism; and to adapt their treatment based on TG and TT that have been previously identified using biomarkers or specific diagnostic tests (Figure 1).

\section{Therapeutic Goals and Treatable Traits in CAD}

We argue that it is reasonable to separate clinical needs what we want to improve in each patient (TG) - from the characteristics (TT) upon which action may be taken in order to achieve this improvement. The definitions proposed for TG and TT are summarised in Table 1. We acknowledge that scientific evidence is still scarce in some cases, but we believe this approach offers practical advantages when it comes to deciding on therapeutic interventions for specific patients. In this article, we will discuss the TG and TT in $\mathrm{CAD}$, and we will show that the different diseases making it

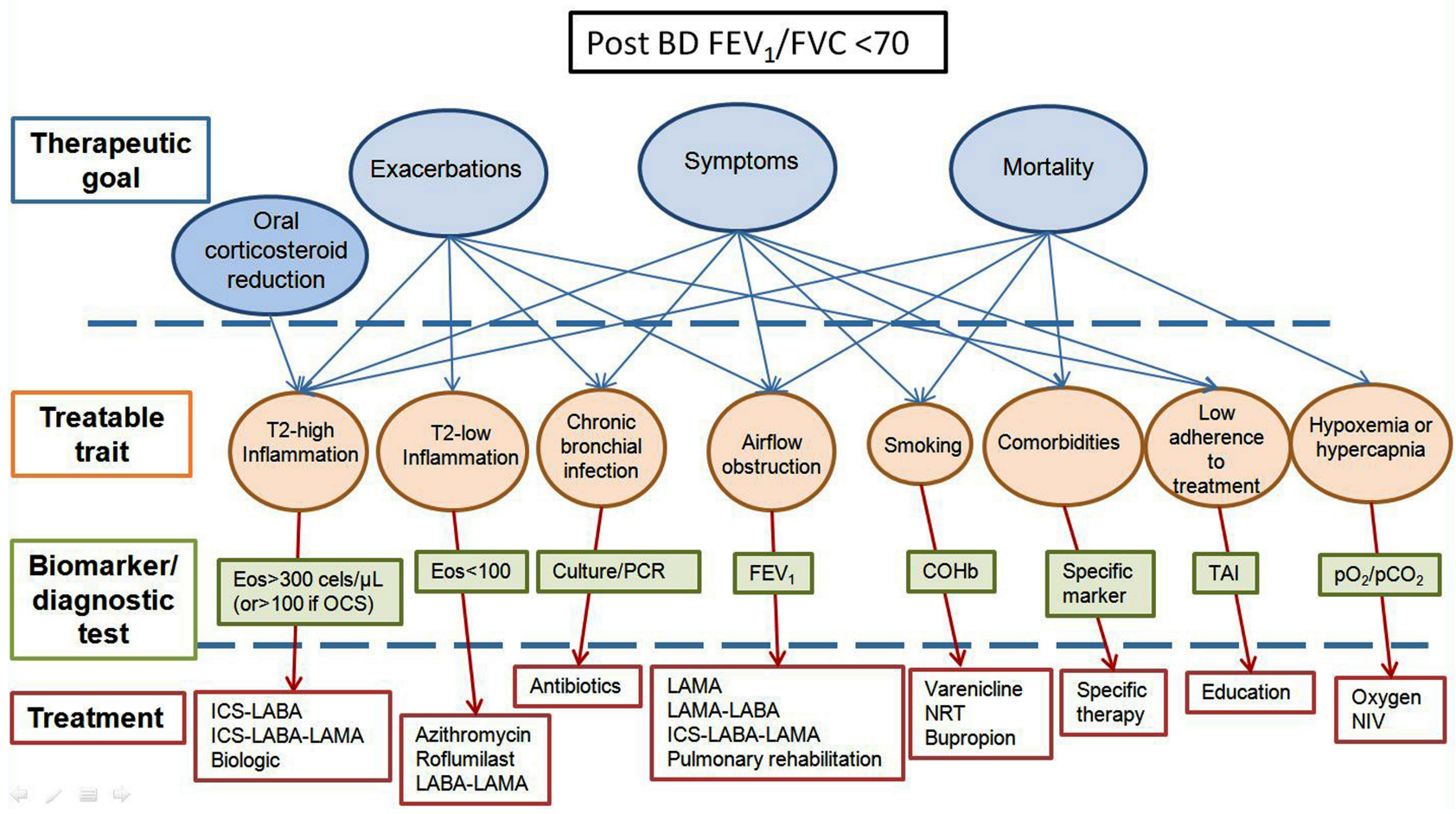

Figure I Conceptual approach to treatment of CAD.

Abbreviations: Eos, eosinophils; OCS, oral corticosteroids; PCR, polymerase chain reaction; FEV, Forced expiratory volume in I second; COHb, carboxyhemoglobin; TAl, test of the adherence to inhalers; $\mathrm{PO}_{2}$, partial pressure of oxygen; $\mathrm{pCO}_{2}$, partial pressure of carbon dioxide; ICS, inhaled corticosteroids; LABA, long-acting beta agonists; LAMA, long-acting muscarinic antagonists; NRT, nicotine replacement therapy; NIV, non-invasive ventilation. 
Table I Definition and Characteristics of Therapeutic Goals and Treatable Traits

\begin{tabular}{|l|l|l|}
\hline & Definition & Characteristics \\
\hline Therapeutic goals & $\begin{array}{l}\text { These are the clinical needs of patients (symptoms, } \\
\text { exacerbations, quality of life, physical activity) or aspects of } \\
\text { the disease upon which action must be taken to improve } \\
\text { their prognosis (progression of the disease, mortality) }\end{array}$ & $\begin{array}{l}\text {-These are not therapeutic targets, but rather clinical } \\
\text { problems that must be eliminated or improved } \\
\text {-Most patients have several TG } \\
\text {-It is possible to improve different TG with a single } \\
\text { therapeutic intervention }\end{array}$ \\
\hline Treatable traits & $\begin{array}{l}\text { These are the clinical, physiological, or biological } \\
\text { characteristics present in each individual patient, and they are } \\
\text { quantifiable through biomarkers or specific diagnostic tests. } \\
\text { They must have effective treatment to improve the value of } \\
\text { the variable }\end{array}$ & $\begin{array}{l}\text {-They must themselves have an impact on one of the TG } \\
\text { (that there must be a clear relationship between the value } \\
\text { eg: more eosinophils, more exacerbations) } \\
\text {-Treatment, through the improvement of the value of the } \\
\text { treatable trait must, as a result, improve one or more TG }\end{array}$ \\
\hline
\end{tabular}

up (asthma, COPD, bronchiectasis ...) basically coincide in these. Table 2 summarises the TG and TT in CAD.

\section{Therapeutic Goals}

Two types of TG can be considered: symptomatic improvement, and reduction of the risks involved in the disease and its treatment. The main TG is a reduction in mortality, something that has already been achieved in asthma with the use of inhaled corticosteroids (ICS); ${ }^{10}$ however, even in developed countries, deaths are still recorded, but they are nearly always associated to poor social conditions. ${ }^{11}$ COPD is a disease with a high mortality rate, although to date few strategies have been proven to be effective in reducing it (for instance, giving up smoking).

Exacerbations have a high impact on the quality of life of asthmatics, ${ }^{12}$ as they are risk factors for mortality, ${ }^{13}$ and also for loss of lung function. ${ }^{14}$ In COPD and bronchiectasis, control of exacerbations is also an evident TG, as these events worsen the quality of life of patients and their prognosis. ${ }^{15,16}$ Lastly, it is of vital importance to avoid the iatrogeny associated with the treatment, which is especially evident in the case of systemic corticosteroids. ${ }^{17}$

Control of symptoms, particularly dyspnoea, is an indisputable TG in CAD, taking into account its relationship to the quality of life of patients. Besides, in the case of asthma, poor symptomatic control represents a greater risk of exacerbations, ${ }^{18}$ and in COPD it is independently associated with mortality. ${ }^{19}$

\section{Treatable Traits}

* Therapeutic non-adherence (TN). It is well established that $\mathrm{TN}$ in asthma is a risk factor for exacerbations. ${ }^{20}$ However, different reminder systems (e-mails, telephone ...) have been shown to improve adherence ${ }^{21}$ and, although some doubts still persist concerning their impact on asthma control ${ }^{22}$ it seems reasonable to detect and reduce TN. Patients with poor

Table 2 Therapeutic Goals and Treatable Traits in CAD

\begin{tabular}{|l|l|l|}
\hline Therapeutic Goals & Treatable Traits & $\begin{array}{l}\text { Biomarker Associated to Therapeutic } \\
\text { Trait }\end{array}$ \\
\hline Reduction of symptoms: & - Bronchial obstruction & $-\mathrm{FEV}_{1}$ \\
-Dyspnoea & - Non-adherence & - Questionnaires \\
- -Night awakenings & - Aggravating factors (allergens, environmental pollution, etc.) & - -Environmental levels \\
-Health-related quality of life & - Smoking & - CO-oximetry \\
Reduction of risk: & - Comorbidities & - -Variable in each case \\
-Reduce mortality & -Eosinophilia & - Eosinophils in blood or airways \\
-Reduce progression of the disease & - Chronic infection & - Germ isolation \\
- Prevent exacerbations & - Chronic bronchitis & - Chronic bronchitis \\
-Reduce adverse effects of & - Chronic hypoxemia & $-\mathrm{PaO}_{2} / \mathrm{SaO}_{2}$ \\
medication & - Chronic hypercapnia & $-\mathrm{PaCO}_{2}$ \\
& -Deficit of alfal-AT & $-\mathrm{AAT}_{\text {levels }}$ \\
& -Lung hyperinflation & - Inspiratory capacity \\
\hline
\end{tabular}


adherence to the treatments used in COPD are at greater risk of being hospitalised and even passing away. ${ }^{23,24}$ Some interventions may improve therapeutic adherence in this disease. $^{24}$

* Tobacco use. Smoking worsens asthma control in a dose-dependent way. ${ }^{25}$ However, giving up the habit improves both the lung function and symptoms of asthmatics. ${ }^{26}$ Carrying on smoking bears a strong relationship to morbidity and mortality in COPD, whereas giving it up is associated to clear improvements in survival rates. ${ }^{27}$

* Comorbidities. The presence of certain comorbidities associated with asthma are linked to poorer control of the disease $^{28}$ and specific treatment for any of them improves it, as occurs for instance with polyposis and obstructive apnoea syndrome during sleep. ${ }^{29,30}$ Patients with COPD and bronchiectasis suffer from numerous comorbidities that aggravate their prognosis. ${ }^{31-34}$ Nevertheless, these must be considered independent diseases that require specific treatment which, on most occasions, does not depend on their association with chronic airway disease. Gastroesophageal reflux is associated with a greater risk of exacerbations, but there is no definitive evidence that its treatment reduces its incidence. ${ }^{35}$

* Bronchial obstruction. In asthma, $\mathrm{FEV}_{1}$ below $80 \%$ of the theoretical value is an independent predictor of exacerbations $^{36}$ and poor lung function is related (albeit imperfectly) to symptoms of the disease. ${ }^{37}$ Further, several clinical trials have demonstrated that tiotropium added to a combination of inhaled corticosteroids and long-acting $\beta-2$ agonists (ICS/LABA) in poorly controlled asthmatics with bronchial obstruction achieves significant functional improvement (approximately $100 \mathrm{~mL}$ ), resulting in a $21 \%$ reduction of exacerbations, ${ }^{38}$ accompanied by symptomatic improvement independently of blood eosinophils. ${ }^{39}$ In COPD, bronchial obstruction is associated with greater mortality, more symptoms, and more exacerbations. ${ }^{40}$ Other measurements of airflow obstruction such as air trapping or lung hyperinflation would need to be explored.

* T2 Inflammation. The presence of T2 inflammation, measured by the presence of eosinophils, both local and peripheral is associated with poorer asthma control and more exacerbations. ${ }^{41}$ Besides, it has been proven that eosinophilia is a good predictor of the response to corticosteroids, ${ }^{42}$ and that adjusting the treatment of severe asthma on the basis of sputum eosinophilia reduces exacerbations. ${ }^{43}$ The role of the monoclonal antibodies antiinterleuquina-5 (anti-IL-5) and anti-IL4 and 13 in the treatment of severe eosinophilic asthma has been perfectly established. $^{44}$

Eosinophilia, measured in induced sputum or in peripheral blood, is a good marker of the therapeutic response to ICS also in COPD. Due to the difficulty in using sputum eosinophilia as a biomarker in usual clinical practice, blood eosinophilia is emerging as the most useful TT biomarker in order to decide about the use of ICS as maintenance treatment in COPD. ${ }^{45-50}$

* Chronic bronchial infection. The isolation of potentially pathogenic microorganisms (PPMs) in bronchial secretions of patients with COPD is considered to be a chronic infection, instead of a colonization. ${ }^{51}$ Colonization implies no harm to the host, and, by definition, it would not require any type of treatment, but PPMs in stable COPD are associated with increased inflammation, increased frequency and severity of exacerbations and faster decline in pulmonary function; therefore, the term colonization is no longer considered adequate. ${ }^{52}$ Regarding the treatment of chronic bronchial infection in chronic airway diseases, there is limited experience in asthma and COPD. The isolation of Pseudomonas aeruginosa has been shown to be associated to a greater risk of exacerbation in asthma, and the AMAZES study evidenced that azithromycin at a dose of $500 \mathrm{mg} 3$ times a week, as a treatment added to the usual medication, is capable of reducing severe exacerbations and improving the quality of life of poorly controlled asthmatics despite a combination of ICS/LABA. ${ }^{53}$ Several studies have demonstrated that long-term treatment with macrolides reduces exacerbations in COPD. ${ }^{54-56}$

Clinical trials of intermittent treatment with quinolones in patients with chronic bronchial infection have been shown to decrease exacerbations. ${ }^{57}$ However, this treatment is not currently recommended due to the risk of inducing resistance against a first-line drug in the management of exacerbations.

The greatest experience is in bronchiectasis and, therefore, we consider that treatment must follow the recommendations of antibiotic treatment of chronic bronchial infection in bronchiectasis. ${ }^{58}$ According to the pathogen, the antimicrobial resistance pattern and the clinical manifestations, treatment may consist of a course of antibiotics, the long-term use of macrolides or inhaled antibiotics.

* Chronic bronchitis. Patients with COPD and chronic bronchitis suffer more exacerbations, have a poorer quality of life, and experience greater loss of lung function than subjects without a production of sputum. ${ }^{59}$ Mucolytics 
could also have a beneficial effect in patients with emphysema owing to their antioxidising action, but another drug used to reduce exacerbations, roflumilast, is indicated only in patients with chronic bronchitis. ${ }^{60}$

In patients with asthma, mucous hypersecretion is associated with more symptoms, more obstruction, and more exacerbations. ${ }^{61}$ Furthermore, in this case, roflumilast has revealed improvement of symptoms and lung function in asthmatics when added to montelukast, in comparison to this drug used in monotherapy. ${ }^{62}$

* Respiratory insufficiency. Severe chronic hypoxemia is a factor associated with a rise in mortality in COPD, and its correction is one of the few interventions known to increase survival in the disease, wherefore it constitutes an evident TT. ${ }^{63,64}$ Chronic hypercapnic respiratory insufficiency is associated with greater risk of mortality, ${ }^{65}$ which could be modified through the use of non-invasive ventilation (even though there are some discordant studies in this regard), ${ }^{66-68}$ in which case it could also be considered a treatable trait.

* In contrast, we do not consider the following to be TT at this time, due to a lack of clear evidence in some of the fundamental aspects (although this is something that could change in the future):

- Exhaled nitric oxide fraction (FeNO). Despite the fact that this is widely used clinically, there is ongoing controversy as to whether adjusting treatment on the basis of its values improves asthma control, and neither is there a well-established cut-off point separating what is normal from pathological; consequently, a recent review in the Cochrane database advises against this indication (except, perhaps, in patients with frequent exacerbations). ${ }^{69}$ In COPD, something similar happens: its persistent high levels seem to be associated to a greater risk of exacerbation of COPD, ${ }^{70,71}$ but a therapeutic strategy based on this biomarker has not yet been demonstrated to have an impact on clinical results, and neither has the best cut-off points been established as yet.

-Allergy. Immunotherapy is not indicated in severe asthma, which usually presents with non-reversible bronchial obstruction, and allergic avoidance is not well established in this context.

- Bronchial hyperresponsiveness (BHR). Asthma control and degree of BHR do not show a close relationship and a large percentage of patients with good control of the disease exhibit ongoing BHR. Further, bronchoprovocation tests are contraindicated with $\mathrm{FEV}_{1}<65 \%$ and their relative complexity means they are not routinely carried out, not even in expert consultations. The AMPUL study ${ }^{72}$ demonstrated that adjusting medication on the basis of methacholine test results could improve lung function and reduce exacerbations (mild ones), but a single study does not seem to be enough to justify considering BHR a TT.

In COPD, BHR appears to be a biomarker that is able to identify subgroups of patients with greater risk of disease progression and mortality. ${ }^{73}$ These subjects could, hypothetically, be the best target group for treatment with ICS, which would confer this variable the character of TT. However, using this trait to indicate treatment with corticosteroids has not yet been demonstrated to produce clinically relevant results.

- Left ventricular diastolic dysfunction associated with lung hyperinflation. Some patients could present an alteration in filling of the left ventricle produced specifically by the hyperinflation associated with COPD. Bronchodilator treatment has been shown to be able to improve left ventricular telediastolic volume in these cases. ${ }^{71}$ Thus, it is conceivable that in the future it will emerge as a new TT in COPD; however, for the time being, information is limited to a single study, and its relationship with dyspnoea, mortality, and other clinical outcomes has not yet been proven, whereby it is still premature to consider it as such.

\section{Unified Treatment of CAD and Controversial Points}

Figure 1 shows a unified conceptual approach to the treatment of CAD - independently of the "classical" diagnosis - based on TG and TT using their biomarkers or specific diagnostic tests. This conceptual approach poses a series of problems in clinical practice:

The definition of "high T2": It seems evident that blood eosinophils must be included in this definition. Ideally, eosinophilia should be measured in airways, but this is not feasible from a practical point of view at this time. According to the literature, the reasonable cut-off point appears to be 300 cells $/ \mu \mathrm{L}$. It must be taken into account that eosinophil count is affected by treatment with oral corticosteroids (OCS), high doses of inhaled corticosteroids (ICS), and biological drugs, so historical values should be taken into consideration.

The question also arises as to whether FeNO ought to be considered a marker of "high T2", since high values can be recorded in patients with rhinitis or respiratory infection. Besides, there is no clear cut-off point to 
separate what is normal from abnormal, and each device offers different values of FeNO. Therefore, although its use is widespread in routine clinical practice and it may be useful in some situations, it does not seem advisable at the current time to classify it as a TT.

Meanwhile, neither is the definition of "low T2" clear enough to make it possible to claim that a patient will not benefit from anti-inflammatory treatment with corticosteroids or biological therapy working on T2 inflammation. In COPD there are already data that suggest that an eosinophil count below 100 cells $/ \mu \mathrm{L}$ enables a poor response to ICS to be predicted; ${ }^{74}$ and in asthma, data from the SIENNA study point in the same direction in patients with a low sputum eosinophil count. ${ }^{75}$

- According to this approach, patients classically diagnosed as COPD and "high T2" would be treated with ICS, whereas patients with the diagnosis of asthma and "low T2" would not receive them. There is a good number of published reports to support the former statement, ${ }^{45-50}$ but the evidence to underpin the latter is more limited. Nevertheless, it has been shown that both sputum and blood eosinophilia predict significant response to corticosteroids in asthma patients. ${ }^{76-78}$ Bearing in mind that induced sputum is technically demanding, the number of eosinophils in blood and sputum can be influenced by treatment (particularly systemic and inhaled corticosteroids) and the predictive value of these two biomarkers is far from perfect, it seems risky to leave a patient with bronchial obstruction - a clinical presentation compatible with asthma and a low blood eosinophil count - without ICS. Although blood eosinophil count is universally available, it is an imperfect surrogate for airway eosinophilia and a significant proportion of patients in real life have eosinophil counts between 100 and 300 cells $/ \mu \mathrm{L}$, in which case it would be necessary to draw up a therapeutic approach based on other TT (obstruction, infection, etc.) and/or carry out a therapeutic trial with anti-inflammatory drugs. While novel omics-based signatures have emerged, they have hardly ever been evaluated clinically, although a limited number of investigations have observed that a given gene expression signature in respiratory samples can predict response to corticosteroids. ${ }^{79,80}$

\section{Clinical Trial Proposal}

Evidently, this conceptual approach must be validated in a clinical trial. We propose launching a prospective, multicentre, open-label, double-arm clinical trial. Patients with post-bronchodilator $\mathrm{FEV1/FVC}<0,70$ regardless of the previous diagnosis, and with a significant clinical impact (measured by 2 exacerbations requiring oral corticosteroids or antibiotics in the previous year and ACT $<19$ or CAT $>10$ ) would be recruited and randomized. At one arm, patients would be classified according to their prior diagnosis (asthma, COPD or bronchiectasis) and would be treated in accordance with the recommendations in international guidelines (GINA, GOLD, or ERS bronchiectasis guidelines) ${ }^{81}$ In the other, patients would be treated in accordance with the TG/TT strategy, independently of their original diagnosis. Patients should be stratified according to their level of airflow obstruction severity (to avoid differences between the two groups) in the initial visit. The follow-up period would be 12 months, and adjustments in medication could be made depending on their evolution. The main response variable ought to be the burden the disease represents for the patient, by grouping specific aspects such as severe exacerbations and health status. The main objective would be to demonstrate that the strategy based on TG/TT achieves a greater proportion of controlled patients (without severe exacerbations, and with $\mathrm{ACT} \geq 20$ and CAT $\leq 10$ ). Variables for secondary objectives would be exacerbations, pneumonias, quality of life, and burden of corticosteroid treatment in both arms. As secondary analysis, other variables are to be explored such as FeNO, BHR, sputum eosinophils and microbiota or lung hyperinflation.

\section{Conclusions}

Asthma, COPD, and other obstructive bronchial processes can have similar TG and TT, which enables them to be encompassed in a broader concept: chronic airways disease (CAD). It is possible to develop a therapeutic algorithm that is valid for CAD, based on TG and TT, although the one put forward herein lacks prospective validation (we propose launching a clinical trial) and relies on biomarkers with some limitations in identifying the underlying inflammatory process. We have absolutely no doubt that in the near future we will be able to have more precise tools available in order to decide the treatment for each patient, without the most relevant being the classical clinical diagnosis.

\section{Disclosure}

Luis Perez de Llano declares to have received grants and/ or fees for consultancy or speeches from Novartis, AstraZeneca, GSK, Teva, Boehringer-Ingelheim, Chiesi, Sanofi, Menarini, Mundipharma, and Esteve, and reports grants, 
personal fees, and non-financial support from AstraZeneca, TEVA, and Chiesi, personal fees and nonfinancial support from GSK, Novartis, Mundipharma and Boehringer, personal fees from Sanofi, other from Menarini, and personal fees from Esteve, BIAL, TECHDOW PHARMA, MSD, and ROVI S.A., outside the submitted work;

Marc Miravitlles has received speaking fees from AstraZeneca, Boehringer Ingelheim, Chiesi, Cipla, AstraZeneca, Menarini, Rovi, Bial, Zambon, CSL Behring, Grifols, and Novartis; consulting fees from AstraZeneca, Boehringer Ingelheim, Chiesi, Ferrer, GlaxoSmithKline, Bial, Gebro Pharma, CSL Behring, Laboratorios Esteve, Ferrer, Mereo Biopharma, Verona Pharma, TEVA, pH Pharma, Novartis, and Grifols; and aid for research from GlaxoSmithKline and Grifols, and reports personal fees from AstraZeneca, Boehringer Ingelheim, Chiesi, Cipla, Menarini, Rovi, Bial, Sandoz, Zambon, CSL Behring, Novartis, GlaxoSmithKline, Gebro Pharma, Kamada, Laboratorios Esteve, Ferrer, Mereo Biopharma, Verona Pharma, TEVA, Spin Therapeutics, pH Pharma, Sanofi and Grifols, and grants from GlaxoSmithKline and Grifols, outside the submitted work. Rafael Golpe declares that he has received speaking or advisory fees, or economic aid to attend congresses from Astra-Zeneca, GSK, Novartis, Chiesi, Mundipharma, Menarini, TEVA, Grifols, Ferrer, Boehringer-Ingelheim, Rovi, and Gebro. Borja G Cosío declares he has received speaking or advisory fees, or economic aid to attend congresses from Astra-Zeneca, GSK, Novartis, Chiesi, Mundipharma, Menarini, TEVA, Boehringer-Ingelheim, and Rovi and reports personal fees from AstraZeneca, GlaxoSmithKline, Rovi, Boehringer-Ingelheim, Chiesi, Menarini, Rovi, Zambon, Grifols, Novartis, Ferrer, Gebro Pharma, and Laboratorios Esteve, during the conduct of the study. Francisco Javier Alvarez-Gutiérrez declares that in the last 3 years he has received fees for advisory work, lectures, or subsidies to attend congresses and scientific meetings from ALK, AstraZeneca, BIal, Boehringer-Ingelheim, Chiesi, GSK, Menarini, Mundipharma, Novartis, and TEVA. Carolina Cisneros has received speaking fees from AstraZeneca, GSK, TEVA, Menarini, Mundipharma, and Novartis; aid to attend congresses from Chiesi, TEVA, Menarini, and Mundipharma; and fees for advisory work from ALK, AstraZeneca, MundiPharma, TEVA, GSK, and Novartis, and reports grants, personal fees, and non-financial support from AstraZeneca, grants and personal fees from GSK and Novartis, personal fees and non-financial support from
TEVA, Menarini, Chiesi and Mundipharma, and personal fees from ALK, outside the submitted work. Carlos Almonacid declares to have received funding in the last 5 years from Astra-zeneca, GSK, Novartis, Chiesi, Mundipharma, Menarini, and TEVA, by way of aid to attend congresses, or as speaking or consulting fees, and reports grants and personal fees from GSK and AstraZeneca, personal fees from ALK, Novartis, Chiesy, and Mundipharma, and non-financial support from Menarini, outside the submitted work. Eva Martinez-Moragon declares to have received funding in the last 5 years from Astra-zeneca, GSK, ALK, Novartis, Chiesi, Mundipharma, Menarini, and TEVA, by way of aid to attend congresses, as speaking fees, or participation in scientific consultancy. Francisco-Javier GonzalezBarcala has received speaking fees or research grants from ALK, AstraZeneca, Bial, Boehringer Ingelheim, Chiesi, Gebro Pharma, GlaxoSmithKline, Laboratorios Esteve, Menarini, Mundipharma, Novartis, Rovi, Roxall, Stallergenes-Greer, and Teva, and reports speaker fees, consulting fees or research grants from ALK, Astra-Zeneca, Bial, Boehringer Ingelheim, Chiesi, Gebro Pharma, GlaxoSmithKline, Laboratorios Esteve, Menarini, Mundipharma, Novartis, Rovi, Roxall, Stallergenes-Greer and Teva. David Ramos-Barbón reports personal fees from GlaxoSmithKline, AstraZeneca, TEVA Pharmaceuticals, personal fees and non-financial support from Novartis and Chiesi, non-financial support from Boehringer-Ingelheim, and personal fees from BIAL Pharmaceuticals, outside the submitted work. Vicente Plaza declares to have received, in the last 3 years, fees for participating as speaker at meetings sponsored by AstraZeneca, Chiesi, and Novartis, and as a consultant from ALK, AstraZeneca, Bial, Boehringer, MundiPharma, and Sanofi; he received economic aid to attend congresses from AZ, Chiesi, and Novartis; and he received subsidies for research projects from AZ, Chiesi, and Menarini; and reports grants and personal fees from AstraZeneca and Chiesi, grants from Menarini, and personal fees from Sanofi, Mundipharma, Boehringer-Ingelheim, GlaxoSmithKline, and Merck, outside the submitted work. Jose Luis López-Campos has received fees, in the last 3 years, for giving lectures, scientific consultancy, participation in clinical studies, or writing papers for (alphabetical order): AstraZeneca, Boehringer Ingelheim, Chiesi, CSL Behring, Esteve, Ferrer, Gebro, GlaxoSmithKline, Grifols, Menarini, Novartis, Rovi, and Teva, and reports personal fees and non-financial support from AstraZeneca, grants, personal fees, and non-financial support from Boehringer, Chiesi, GSK, Grifols, Menarini, 
and Novartis, personal fees from CSL Behring, Esteve, and Ferrer, grants and personal fees from GebroPharma, and personal fees from Rovi and Teva, outside the submitted work. Ciro Casanova has received fees for giving lectures, scientific consultancy, participation in clinical studies, or writing papers for (alphabetical order): AstraZeneca, Bial, Boehringer Ingelheim, Chiesi, Esteve, Gebro, GlaxoSmithKline, Menarini, Novartis, Rovi, and Teva, and reports nonfinancial support from Astra-Zeneca, personal fees from Bial, Boehringer-Ingelheim, Chiesi, Esteve, and Novartis, personal fees and non-financial support from GSK, and grants and non-financial support from Menarini, outside the submitted work. Juan Luis Rodriguez Hermosa has received speaking fees from Boehringer Ingelheim and Gebro Pharma and reports personal fees from Boehringer Ingelheim, Grifols, Gebro, and Glaxo, outside the submitted work. Myriam Calle Rubio has received speaking fees from Boehringer Ingelheim, AstraZeneca, GlaxoSmithKline, Menarini, and Novartis; and consulting fees from GlaxoSmith $\neg$ Kline, Gebro Pharma, and Novartis, and reports personal fees from Boehringer Ingelheim, Menarini, Novartis, Gebro, Glaxo, and AstraZeneca, outside the submitted work. JJ Soler-Cataluña declares to have received fees for giving lectures, scientific consultancy, or participation in clinical studies on behalf of Air Liquide, AstraZeneca, Boehringer Ingelheim, Chiesi, Esteve, Ferrer, GSK, Menarini, Mundipharma, Novartis, Rovi, Sandoz, and Teva and reports grants and personal fees from AstraZeneca, Chiesi, and GSK, grants, personal fees, and nonfinancial support from Boehringer-Ingelheim and Novartis, and personal fees from Bial, Ferrer, Rovi, and Teva, outside the submitted work. Borja $\mathrm{G}$ Cosio reports grants and personal fees from AstraZeneca, Chiesi, and GSK, personal fees from Novartis, personal fees and non-financial support from Mundipharma, and grants from Menarini, Teva, BoehringerIngelheim, and Rovi, outside the submitted work. The rest of the authors declare they have no conflict of interests for this work. The rest of the authors declare they have no conflict of interests for this work.

\section{References}

1. Burrows B, Bloom JW, Traver GA, Cline MG. The course and prognosis of different forms of chronic airways obstruction in a sample from the general population. N Engl J Med. 1987;317(21):1309-1314. doi:10.1056/NEJM198711193172103

2. Orie NG, Slutter HJ de VRIE, Tammeling GJ. Chronic nonspecific respiratory diseases. Ned Tijdschr Geneeskd. 1961;28(105):2136-2139.

3. Lange P, Celli B, Agusti A, et al. Lung-function trajectories leading to chronic obstructive pulmonary disease. $N$ Engl J Med. 2015;373 (2):111-122. doi:10.1056/NEJMoa1411532
4. Barnes PJ. Asthma-COPD Overlap. Chest. 2016;149(1):7-8. doi:10.1016/j.chest.2015.08.017

5. Miravitlles M, Alvarez-Gutierrez FJ, Calle M, et al. Algorithm for identification of asthma-COPD overlap: consensus between the Spanish COPD and asthma guidelines. Eur Respir J. 2017;49 (5):1700068. doi:10.1183/13993003.00068-2017

6. Pérez-de-Llano L, Cosio BG. Asthma-COPD overlap is not a homogeneous disorder: further supporting data. Respir Res. 2017;18(1):183. doi:10.1186/s12931-017-0667-x

7. Agusti A, Bel E, Thomas M, et al. Treatable traits: toward precision medicine of chronic airway diseases. Eur Respir J. 2016;47 (2):410-419. doi:10.1183/13993003.01359-2015

8. Pavord ID, Beasley R, Agusti A, et al. After asthma: redefining airways diseases. Lancet. 2017;S0140-6736(17)30879-6.

9. McDonald VM, Fingleton J, Agusti A, et al. Treatable traits: a new paradigm for 21 st century management of chronic airway diseases: treatable traits down under international workshop report. Eur Respir J. 2019;53(5):1802058. doi:10.1183/13993003.02058-2018

10. Suissa S, Ernst P, Benayoun S, Baltzan M, Cai B. Low-dose inhaled corticosteroids and the prevention of death from asthma. $N$ Engl $J$ Med. 2000;343(5):332-336. doi:10.1056/NEJM200008033430504

11. Gupta RP, Mukherjee M, Sheikh A, Strachan DP. Persistent variations in national asthma mortality, hospital admissions and prevalence by socioeconomic status and region in England. Thorax. 2018;73(8):706-712. doi:10.1136/thoraxjnl-2017-210714

12. Mroczek B, Kurpas D, Urban M, Sitko Z, Grodzki T. The influence of asthma exacerbations on health-related quality of life. Adv Exp Med Biol. 2015;873:65-77.

13. McCoy L, Redelings M, Sorvillo F, Simon P. A multiple cause-ofdeath analysis of asthma mortality in the United States, 1990-2001. J Asthma. 2005;42(9):757-763. doi:10.1080/02770900500308189

14. O’Byrne PM, Pedersen S, Lamm CJ, Tan WC, Busse WW. START investigators group. Severe exacerbations and decline in lung function in asthma. Am J Respir Crit Care Med. 2009;179(1):19-24. doi:10.1164/rccm.200807-1126OC

15. Soler-Cataluña JJ, Martínez-García MA, Román Sánchez P, Salcedo E, Navarro M, Ochando R. Severe acute exacerbations and mortality in patients with chronic obstructive pulmonary disease. Thorax. 2005;60(11):925-931. doi:10.1136/thx.2005.040527

16. Martínez-García MA, Athanazio R, Gramblicka G, Corso M, Cavalcanti Lundgre F. Prognostic value of frequent exacerbations in bronchiectasis: the relationship with disease severity. Arch Bronconeumol. 2019;55(2):81-87. doi:10.1016/j.arbres.2018.07.002

17. Bloechliger M, Reinau D, Spoendlin J, et al. Adverse events profile of oral corticosteroids among asthma patients in the UK: cohort study with a nested case-control analysis. Respir Res. 2018;19(1):75. doi:10.1186/s12931-018-0742-y

18. Ko FW, Hui DS, Leung TF, et al. Evaluation of the asthma control test: a reliable determinant of disease stability and a predictor of future exacerbations. Respirology. 2012;17(2):370-378. doi:10.1111/ j.1440-1843.2011.02105.x

19. Casanova C, Marín JM, Martínez-González C, et al. Differential effect of modified medical research council dyspnea, COPD assessment test and clinical COPD questionnaire for symptoms evaluation within the new GOLD staging and mortality in COPD. Chest. 2015;148(1):159-168. doi:10.1378/chest.14-2449

20. Engelkes M, Janssens HM, de Jongste JC, Sturkenboom MC, Verhamme KM. Medication adherence and the risk of severe asthma exacerbations: a systematic review. Eur Respir J. 2015;45 (2):396-407. doi:10.1183/09031936.00075614

21. Tran N, Coffman JM, Sumino K, Cabana MD. Patient reminder systems and asthma medication adherence: a systematic review. J Asthma. 2014;51(5):536-543. doi:10.3109/02770903.2014.888572

22. Normansell R, Kew KM, Stovold E. Interventions to improve adherence to inhaled steroids for asthma. Cochrane Database Syst Rev. 2017;18(4):CD012226. 
23. Vestbo J, Anderson JA, Calverley PM, et al. Adherence to inhaled therapy, mortality and hospital admission in COPD. Thorax. 2009;64 (11):939-943. doi:10.1136/thx.2009.113662

24. Bryant J, McDonald VM, Boyes A, Sanson-Fisher R, Paul C, Melville J. Improving medication adherence in chronic obstructive pulmonary disease: a systematic review. Respir Res. 2013;14(1):109. doi:10.1186/1465-9921-14-109

25. Polosa R, Russo C, Caponnetto P, et al. Greater severity of new onset asthma in allergic subjects who smoke: a 10-year longitudinal study. Respir Res. 2011;12(1):16. doi:10.1186/1465-9921-12-16

26. Chaudhuri R, Livingston E, McMahaon AD, et al. Effects of smoking cessation on lung function and airway inflammation in smokers with asthma. Am J Respir Crit Care Med. 2006;174(2):127-133. doi:10.11 64/rccm.200510-1589OC

27. Godtfredesen NS, Lam TH, Hansel TT, et al. COPD-related morbidity and mortality after smoking cessation: status of the evidence. Eur Respir J. 2008;32(4):844-853. doi:10.1183/09031936.00160007

28. Pérez De Llano LA, González FC, Añón OC, Perea MP, Caruncho MV, Villar AB. Relationship between comorbidity and asthma control. Arch Bronconeumol. 2010;46(10):508-513. doi:10.10 16/j.arbres.2010.05.008

29. Bachert C, Zhang L, Gevaert P. Current and future treatment options for adult chronic rhinosinusitis: focus on nasal polyposis. $J$ Allergy Clin Immunol. 2015;136(6):1431-1440. doi:10.1016/j.jaci.2015.10. 010

30. Serrano-Pariente J, Plaza V, Soriano JB, et al. CPASMA trial group. Asthma outcomes improve with continuous positive airway pressure for obstructive sleep apnea. Allergy. 2017;72(5):802-812. doi:10.11 11/all.13070

31. Divo M, Cote C, de Torres JP, et al. Comorbidities and risk of mortality in patients with chronic obstructive pulmonary disease. Am J Respir Crit Care Med. 2012;186(2):155-161. doi:10.1164/ rccm.201201-0034OC

32. Figueira Gonçalves JM, García Bello MÁ, Martín Martínez MD, García-Talavera I, Golpe R. Can the COPD-comorbidome be applied to all outpatients with chronic obstructive pulmonary disease? A single-center analysis. Arch Bronconeumol. 2019;S0300-2896(19)30212-1. doi:10.1016/j.arbres.2019.03.016

33. Mc Donnell MJ, Aliberti S, Goeminne PC, et al. Comorbidities and the risk of mortality in patients with bronchiectasis: an international multicentre cohort study. Lancet Respir Med. 2016;4(12):969-979. doi:10.1016/S2213-2600(16)30320-4

34. Marín JM, Soriano JB, Carrizo SJ, Boldova A, Celli BR. Outcomes in patients with chronic obstructive pulmonary disease and obstructive sleep apnea: the overlap syndrome. Am J Respir Crit Care Med. 2010;182(3):325-331. doi:10.1164/rccm.200912-1869OC

35. Benson VS, Müllerova H, Vestbo J, Wedzicha JA, Patel A, Hurst JR. Evaluation of COPD longitudinally to identify predictive surrogate endpoints (ECLIPSE) investigators. Associations between gastro-oesophageal reflux, its management and exacerbations of chronic obstructive pulmonary disease. Respir Med. 2015;109 (9):1147-1154. doi:10.1016/j.rmed.2015.06.009

36. Kitch BT, Paltiel AD, Kuntz KM, et al. A single measure of $\mathrm{FEV}_{1}$ is associated with risk of asthma attacks in long-term follow-up. Chest. 2004;126(6):1875-1882. doi:10.1378/chest.126.6.1875

37. Schatz M, Sorkness CA, Li JT, et al. Asthma control test: reliability, validity, and responsiveness in patients not previously followed by asthma specialists. J Allergy Clin Immunol. 2006;117(3):549-556. doi:10.1016/j.jaci.2006.01.011

38. Kerstjens HA, Engel M, Dahl R, et al. Tiotropium in asthma poorly controlled with standard combination therapy. $N$ Engl J Med. 2012;367(13):1198-1207. doi:10.1056/NEJMoa1208606

39. Casale TB, Bateman ED, Vandewalker M, et al. Tiotropium respimat add-on is efficacious in symptomatic asthma, independent of T2 phenotype. J Allergy Clin Immunol Pract. 2018;6(3):923-935. doi:10.1016/j.jaip.2017.08.037
40. Celli BR, Cote CG, Marín JM, et al. The body-mass index, airflow obstruction, dyspnea, and exercise capacity index in chronic obstructive pulmonary disease. $N$ Engl J Med. 2004;350(10):1005-1012. doi:10.1056/NEJMoa021322

41. Schleich FN, Chevremont A, Paulus V, et al. Importance of concomitant local and systemic eosinophilia in uncontrolled asthma. Eur Respir J. 2014;44(1):97-108. doi:10.1183/09031936.00201813

42. Cowan DC, Taylor DR, Peterson LE, et al. Biomarker-based asthma phenotypes of corticosteroid response. J Allergy Clin Immunol. 2015;135(4):877-883. doi:10.1016/j.jaci.2014.10.026

43. Petsky HL, Li A, Chang AB. Tailored interventions based on sputum eosinophils versus clinical symptoms for asthma in children and adults. Cochrane Database Syst Rev. 2017;24(8):CD005603.

44. Farne HA, Wilson A, Powell C, Bax L, Milan SJ. Anti-IL5 therapies for asthma. Cochrane Database Syst Rev. 2017;21(9):CD010834.

45. Siddiqui SH, Guasconi A, Vestbo J, et al. Blood eosinophils: a biomarker of response to extrafine beclomethasone/formoterol in chronic obstructive pulmonary disease. Am J Respir Crit Care Med. 2015;192(4):523-525. doi:10.1164/rccm.201502-0235LE

46. Pavord ID, Lettis S, Locantore N, et al. Blood eosinophils and inhaled corticosteroid/long-acting $\beta-2$ agonist efficacy in COPD. Thorax. 2016;71(2):118-125. doi:10.1136/thoraxjnl-2015-207021

47. Pascoe S, Locantore N, Dransfield MT, Barnes NC, Pavord ID. Blood eosinophil counts, exacerbations, and response to the addition of inhaled fluticasone furoate to vilanterol in patients with chronic obstructive pulmonary disease: a secondary analysis of data from two parallel randomized controlled trials. Lancet Respir Med. 2015;3(6):435-442. doi:10.1016/S2213-2600(15)00106-X

48. Hinds DR, DiSantostefano RL, Le HV, Pascoe S. Identification of responders to inhaled corticosteroids in a chronic obstructive pulmonary disease population using cluster analysis. BMJ Open. 2016;6 (6):e010099. doi:10.1136/bmjopen-2015-010099

49. Watz H, Tetzlaff K, Wouters EF, et al. Blood eosinophil count and exacerbations in severe chronic obstructive pulmonary disease after withdrawal of inhaled corticosteroids: a post-hoc analysis of the WISDOM trial. Lancet Respir Med. 2016;4(5):390-398. doi:10. 1016/S2213-2600(16)00100-4

50. Chapman KR, Hurst JR, Frent SM, et al. Long-term triple therapy de-escalation to indacaterol/glycopyrronium in patients with chronic obstructive pulmonary disease (SUNSET): a randomized, double-blind, triple-dummy clinical trial. Am J Respir Crit Care Med. 2018;198(3):329-339. doi:10.1164/rccm.201803-0405OC

51. de la Rosa Carrillo D, López-Campos JL, Alcázar Navarrete B, et al. Consensus document on the diagnosis and treatment of chronic bronchial infection in chronic obstructive pulmonary disease. Arch Bronconeumol. 2020;S0300-2896(20)30145-9. doi:10.1016/j.arbres.2020.04.023

52. López-Campos JL, Miravitlles M, De la Rosa Carrillo D, Cantón R, Soler-Cataluña JJ, Martínez-García MA. Current challenges in chronic bronchial infection in patients with chronic obstructive pulmonary disease. J Clin Med. 2020;9(6):E1639. doi:10.3390/jcm90 61639

53. Gibson PG, Yang IA, Upham JW, et al. Effect of azithromycin on asthma exacerbations and quality of life in adults with persistent uncontrolled asthma (AMAZES): a randomised, double-blind, placebo-controlled trial. Lancet. 2017;390(10095):659-668. doi:10. 1016/S0140-6736(17)31281-3

54. Seemungal TAR, Wilkinson TMA, Hurst JR, Perera WR, Sapsford RJ, Wedzicha JA. Long-term erythromycin therapy is associated with decreased chronic obstructive pulmonary disease exacerbations. Am J Respir Crit Care Med. 2008;178(11):11 39-1147. doi:10.1164/rccm.200801-145OC

55. Uzun S, Djamin RS, Kluytmans JA, et al. Azithromycin maintenance treatment in patients with frequent exacerbations of chronic obstructive pulmonary disease (COLUMBUS): a randomized, double-blind, placebo-controlled trial. Lancet Respir Med. 2014;2(5):361-368. doi:10.1016/S2213-2600(14)70019-0 
56. Albert RK, Connett J, Bailey WC, et al. Azithromycin for prevention of exacerbations of COPD. N Engl J Med. 2011;365(8):689-698. doi:10.1056/NEJMoa1104623

57. Sethi S, Jones PW, Theron MS, et al. Pulsed moxifloxacin for the prevention of exacerbations of chronic obstructive pulmonary disease: a randomized controlled trial. Respir Res. 2010;11(1):10. doi:10.1186/1465-9921-11-10

58. Martinez-Garcia MA, Maiz L, Olveira C, et al. Spanish guidelines on treatment of bronchiectasis in adults. Arch Bronconeumol. 2018;54 (2):88-98. doi:10.1016/j.arbr.2017.07.014

59. Kim V, Han MK, Vance GB, et al. The chronic bronchitis phenotype of COPD: an analysis of the COPDGene study. Chest. 2011;140 (3):626-633. doi:10.1378/chest.10-2948

60. Wedzicha JA, Calverley PM, Rabe KF. Roflumilast: a review of its use in the treatment of COPD. Int J Chron Obstruct Pulmon Dis. 2016;6(11):81-90. doi:10.2147/COPD.S89849

61. Martínez-Rivera C, Crespo A, Pinedo-Sierra C, et al. Mucus hypersecretion in asthma is associated with rhinosinusitis, polyps and exacerbations. Respir Med. 2018;135:22-28. doi:10.1016/j.rmed.2017.12.013

62. Bateman ED, Goehring UM, Richard F, Watz H. Roflumilast combined with montelukast versus montelukast alone as add-on treatment in patients with moderate-to-severe asthma. J Allergy Clin Immunol. 2016;138(1):142-149. doi:10.1016/j.jaci.2015.11.035

63. Report of the Medical Research Council Working Party. Long-term domiciliary oxygen therapy in chronic hypoxic cor pulmonale complicating chronic bronchitis and emphysema. Lancet. 1981;681-685.

64. Nocturnal Oxygen Therapy Trial group. Continuous or nocturnal oxygen therapy in hypoxemic chronic obstructive lung disease. Ann Intern Med. 1980;93(3):391-398. doi:10.7326/0003-4819-93-3-391

65. Foucher P, Baudoin N, Merati M, et al. Relative survival analysis of 252 patients with COPD receiving long-term oxygen therapy. Chest. 1998;6(6):1580-1587. doi:10.1378/chest.113.6.1580

66. Köhnlein T, Windisch W, Köhler D, et al. Non-invasive positive pressure ventilation for the treatment of severe stable chronic obstructive pulmonary disease: a prospective, multicentre, randomised, controlled clinical trial. Lancet Respir Med. 2014;2 (9):698-705. doi:10.1016/S2213-2600(14)70153-5

67. Murphy PB, Rehal S, Àrbane G, et al. Effect of home noninvasive ventilation with oxygen therapy vs oxygen therapy alone on hospital readmission or death after an acute COPD exacerbation: a randomized clinical trial. JAMA. 2017;317(21):2177-2186. doi:10. 1001/jama.2017.4451

68. Struik FM, Sprooten RT, Kerstjens HA, et al. Nocturnal non-invasive ventilation in COPD patients with prolonged hypercapnia after ventilator support for acute respiratory failure: a randomized, controlled, parallel-group study. Thorax. 2014;69(9):826-834. doi:10.1136/thoraxjnl-2014-205126

69. Petsky HL, Kew KM, Turner C, Chang AB. Exhaled nitric oxide levels to guide treatment for adults with asthma. Cochrane Database Syst Rev. 2016;1(9):CD011440.
70. Alcázar-Navarrete B, Castellano Miñán F, Santiago Díaz P, Ruiz Rodríguez O, Romero Palacios PJ. Alveolar and bronchial nitric oxide in chronic obstructive pulmonary disease and asthma-COPD overlap. Arch Bronconeumol. 2018;54(8):414-419. doi:10.1016/j. arbres.2018.02.006

71. Hohlfeld JM, Vogel-Claussen J, Biller H, et al. Effect of lung deflation with indacaterol plus glycopyrronium on ventricular filling in patients with hyperinflation and COPD (CLAIM): a double-blind, randomised, crossover, placebo-controlled, single-centre trial. Lancet Respir Med. 2018;6(5):368-378. doi:10.1016/S2213-2600(18)30054-7

72. Sont JK, Willems LN, Bel EH, van Krieken JH, Vandenbroucke JP, Sterk PJ. Clinical control and histopathologic outcome of asthma when using airway hyperresponsiveness as an additional guide to long-term treatment. The AMPUL study group. Am J Respir Crit Care Med. 1999;159(4):1043-1051. doi:10.1164/ajrccm.159.4.9806052

73. Hospers JJ, Postma DS, Rijcken B, Weiss ST, Schouten JP. Histamine airway hyper-responsiveness and mortality from chronic obstructive pulmonary disease: a cohort study. Lancet. 2000;356(9238):13 13-1317. doi:10.1016/S0140-6736(00)02815-4

74. Bafadhel M, Peterson S, De Blas MA, et al. Predictors of exacerbation risk and response to budesonide in patients with chronic obstructive pulmonary disease: a post-hoc analysis of three randomised trials. Lancet Respir Med. 2018;6(2):117-126. doi:10.1016/S22132600(18)30006-7

75. Lazarus SC, Krishnan JA, King TS, et al. Mometasone or tiotropium in mild asthma with a low sputum eosinophil level. $N$ Engl J Med. 2019;380(21):2009-2019. doi:10.1056/NEJMoa1814917

76. Kupczyk M, Haque S, Middelveld RJ, Dahlén B, Dahlén SE. Phenotypic predictors of response to oral glucocorticosteroids in severe asthma. Respir Med. 2013;107(10):1521-1530. doi:10.1016/ j.rmed.2013.07.014

77. Ten Brinke A, Zwinderman AH, Sterk PJ, Rabe KF, Bel EH. "Refractory" eosinophilic airway inflammation in severe asthma: effect of parenteral corticosteroids. Am J Respir Crit Care Med. 2004;170(6):601-605. doi:10.1164/rccm.200404-440OC

78. Wu W, Bang S, Bleecker ER, et al. Multiview cluster analysis identifies variable corticosteroid response phenotypes in severe asthma. Am J Respir Crit Care Med. 2019;199(11):1358-1367. doi:10.1164/rccm.201808-1543OC

79. Woodruff PG, Barmak Modrek DF, Choy GJ, et al. T-helper type 2driven inflammation defines major subphenotypes of asthma. Am J Respir Crit Care Med. 2009;180(5):388-395. doi:10.1164/ rccm.200903-0392OC

80. Berthon BS, Gibson PG, Wood LG. A sputum gene expression signature predicts oral corticosteroid response in asthma. Eur Respir J. 2017;49(6):1700180. doi:10.1183/13993003.00180-2017

81. Polverino E, Goeminne PC, McDonnell MJ, et al. European respiratory society guidelines for the management of adult bronchiectasis. Eur Respir J. 2017;50(3):1700629. doi:10.1183/13993003.00629-2017

International Journal of Chronic Obstructive Pulmonary Disease

\section{Publish your work in this journal}

The International Journal of COPD is an international, peer-reviewed journal of therapeutics and pharmacology focusing on concise rapid reporting of clinical studies and reviews in COPD. Special focus is given to the pathophysiological processes underlying the disease, intervention programs, patient focused education, and self management protocols. This journal is indexed on PubMed Central, MedLine and CAS. The manuscript management system is completely online and includes a very quick and fair peer-review system, which is all easy to use. Visit http://www.dovepress.com/testimonials.php to read real quotes from published authors. 